\title{
Hereditary Hyperferritinemia-cataract Syndrome
}

\section{A Case Report of a Danish Family with a G32T Point Mutation of the FTL Gene}

\author{
Cecilie Utke Rank, ${ }^{1}$ Jesper Petersen, ${ }^{2}$ Henrik Birgens ${ }^{3}$ and Ove Juul Nielsen ${ }^{1}$
}

1. Medical Doctor, Department of Haematology, Rigshospitalet University Hospital, Copenhagen, Denmark; 2. Molecular Biologist; 3. Medical Doctor, Department of Haematology, Herlev University Hospital, Herlev, Denmark

\begin{abstract}
Hereditary hyperferritinemia-cataract syndrome (HHCS) is a rare autosomal dominant disorder associated with high plasma ferritin concentration without iron overload and early-onset bilateral cataract. The deregulation of ferritin production in HHCS is caused by mutations in the iron-responsive elements (IRES) of the ferritin L-subunit gene (FTL gene) - interfering with the high-affinity interaction between IRES and iron regulatory proteins (IRPS), disturbing the negative regulatory control of ferritin synthesis and resulting in excessive production of L-ferritin. We report a 44-year-old woman initially suspected of having hereditary haemochromatosis and later together with family members diagnosed with HHCS. Genetic analysis showed heterozygosity for a G32T point mutation (Paris 2 mutation) in the IRE located in the $5^{\prime}$ untranslated region (UTR) of the FTL gene. The differential diagnosis of hereditary haemochromatosis and HHCS together with the rarity and the versatile phenotype in HHCS obscures the diagnostic process, which emphasises the importance of the correct diagnosis of HHCS in order to prevent unnecessary phlebotomy.
\end{abstract}

\section{Keywords}

Hyperferritinemia-cataract syndrome, HHCS, Paris 2 mutation, hyperferritinemia, cataracts

\begin{abstract}
Disclosure: Cecilie Utke Rank, Jesper Petersen, Henrik Birgens and Ove Juul Nielsen have no conflicts of interest to declare. No funding was received in the publication of this article.

Open Access: This article is published under the Creative Commons Attribution Noncommercial License, which permits any non-commercial use, distribution, adaptation and reproduction provided the original author(s) and source are given appropriate credit.

Compliance with Ethics Guidelines: All procedures were followed in accordance with the responsible committee on human experimentation and with the Helsinki Declaration of 1975 and subsequent revisions. Informed consent was received from the patient involved in this case study.

Received: 1 June 2015 Accepted: 10 July 2015 Citation: European Oncology \& Haematology, 2015;11(2):147-9 DOl: http://doi.org/10.17925/EOH.2015.11.02.147 Correspondence: Cecilie Utke Rank, Department of Haematology, Rigshospitalet, Blegdamsvej 9, 2100 Copenhagen, Denmark. E: cecilieutkerank@gmail.com
\end{abstract}

Hereditary hyperferritinemia-cataract syndrome (HHCS) is a rare autosomal dominant disorder associated with high plasma ferritin concentration without iron overload and early-onset bilateral cataract. HHCS was first described in 1995, ${ }^{1-3}$ and since then over 30 mutations, mainly point mutations and deletions, associated with HHCS have been reported. ${ }^{4-6}$

Isolated hyperferritinemia with plasma ferritin concentrations above $300 \mu \mathrm{g} / \mathrm{l}$ in men and $200 \mu \mathrm{g} / \mathrm{I}$ in women in an asymptomatic patient and in absence of inflammation and liver disease, most likely indicates increased iron stores and requires further investigation whether or not it is accompanied by iron overload - in order to differentiate between hereditary haemochromatosis $(\mathrm{HH})$, haemosiderosis, ferroportin disease, aceruloplasminemia, atransferrinemia and HHCS. ${ }^{7}$

Under normal physiological conditions, plasma ferritin reflects the amount of iron stored in tissue macrophages - apart from infectious, inflammatory, autoimmune and malignant diseases, where plasma ferritin also acts as an acute-phase reactant. Ferritin is composed of different subunits, $L, H$ and $G$, which arrange to form different isoferritins. The synthesis of these ferritin subunits is regulated by iron availability through an iron regulatory system. Iron-responsive elements (IREs) are one component of this system and are mRNA stemloop structures located in the $5^{\prime}$ or in the $3^{\prime}$ untranslated regions (UTRS) of the genes involved in iron metabolism. IREs are crucial in regulating the cellular iron metabolism and coordinating the synthesis of various proteins involved in the iron metabolism, including transferrin receptor for cellular iron uptake, ferritin for intracellular iron storage and erythroid-specific $\delta$-aminolevulinate synthase ( $\delta$-ALAS) for iron use for haemoglobin synthesis. The stem structure of the mRNA is interrupted by several bulges with a terminal loop that is essential for binding of cytoplasmic proteins called iron regulatory proteins (IRPS). IRPS are the other components of the iron regulatory system, which bind to IREs in response to iron deficiency, induce expression of transferrin receptors (increasing iron uptake) and repress the synthesis of ferritin and $\delta$-ALAS (decreasing iron storage and iron use). The opposite occurs in conditions of iron excess. ${ }^{6.8-10}$

The deregulation of ferritin production in HHCS is caused by mutations in the IRES of the FTL gene - interfering with the high-affinity interaction between IRES and IRPS, leading to disrupted down-regulation/negative regulatory control by IRPS of L-ferritin mRNA translation and resulting 
Table 1: Laboratory Findings

\begin{tabular}{|c|c|c|c|c|c|c|c|c|c|}
\hline & $\begin{array}{l}\text { P-ferritin/ } \\
\mu g / l \\
(12-300)\end{array}$ & $\begin{array}{l}\text { P-iron/ } \\
\mu \mathrm{mol} / \mathrm{I} \\
(9-34)\end{array}$ & $\begin{array}{l}\text { P-transferrin/ } \\
\mu \mathrm{mol} / \mathrm{l} \\
(24-41)\end{array}$ & $\begin{array}{l}\text { P-transferrin } \\
\text { Saturation } \\
(0.2-0.5)\end{array}$ & $\begin{array}{l}\mathrm{MCV} / \mathrm{fl} \\
(82-98)\end{array}$ & $\begin{array}{l}\text { P-haemoglobin/ } \\
\mathrm{mmol} / \mathrm{l} \\
(7.3-9.5)\end{array}$ & $\begin{array}{l}\text { P-CRP/ } \\
\text { mg/l }(<10)\end{array}$ & $\begin{array}{l}\text { P-ALAT/ } \\
\text { U/I } \\
(10-45)\end{array}$ & BM Biopsy \\
\hline Proband & 1,400 & 8 & 42.3 & 0.09 & 73 & 8.1 & $<1$ & 15 & $\begin{array}{l}\text { Decreased } \\
\text { amount of } \\
\text { stainable iron }\end{array}$ \\
\hline Daughter of the proband & 1,100 & & & & & & & & \\
\hline Son 1 of the proband & 1,350 & & & & & & & & \\
\hline Son 2 of the proband & 1,150 & & & & & & & & \\
\hline Sister of the proband & 1,490 & & & & & & & & \\
\hline
\end{tabular}

$A L A T=$ alanine aminotransferase; $B M=$ bone marrow; $C R P=C$-reactive protein; $M C V=$ mean corpuscular volume; $)=$ reference range. The darker area represents non-available data.

Figure 1: The G32T Point Mutation of the

\section{FTL Gene}

t mutation

$\begin{array}{llllll}A & & & G & \text { Hairpin } \\ \text { C } & & & U & \\ & A & U & & \\ & A & U & & \\ & C & G & & \\ & U & G & & \\ & \text { U } & \text { A } & & \end{array}$

C

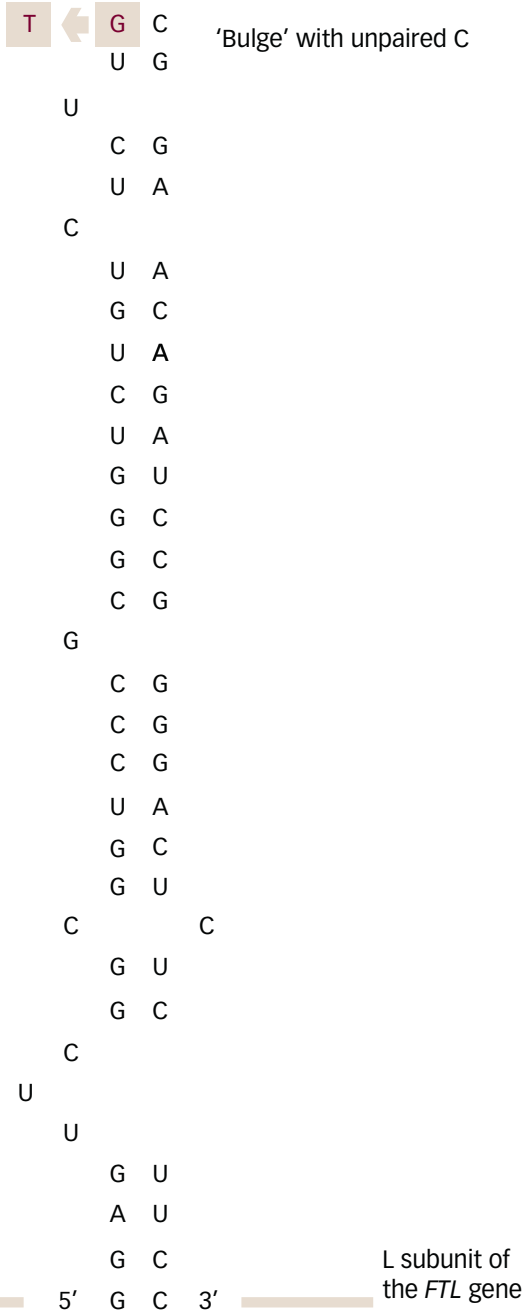

RNA sequence secondary structure of the L-subunit Iron-responsive element and the point mutation located in the $5^{\prime}$ untranslated region of the FTL gene on chromosome 19q: G32 (the Paris 2 mutation). The arrow indicates the nucleotide substitution at position +32 . in excessive production of L-ferritin regardless of the iron level. The only known organ damage in HHCS is cataract, which appears to be a consequence of accumulation of L-ferritin within the lens fibres. ${ }^{8-10}$ Thus, the only treatment available for HHCS is cataract surgery.

\section{Case History}

A 44-year-old Caucasian woman was suspected of having $\mathrm{HH}$ in 2011, when she was referred from the medical department with a plasma ferritin of 1,400 $\mu \mathrm{g} / \mathrm{l}$. She was asymptomatic, and the physical examination was normal. Blood samples showed low plasma iron, low transferrin saturation, decreased mean corpuscular volume (MCV), normal inflammatory markers and normal haemoglobin (see Table 1). The patient was negative for HFE gene mutation (related to $\mathrm{HH}$ ), had normal liver cell counts and liver size and the bone marrow displayed low iron deposits. Apart from hyperferritinemia, the only abnormality was a medical record showing bilateral cataract surgery performed 21 years ago. Thus, the combination of hyperferritinemia not due to iron overload and previous bilateral cataract surgery led the clinicians on the track of HHCS.

\section{Methods}

Plasma ferritin levels and genomic DNA were extracted from peripheral whole blood of each subject.

\section{Molecular Diagnosis}

Genomic DNA was purified from leukocytes using the QIAamp DNA Blood Mini QIAcube Kit. The $5^{\prime}$ UTR region of the FTL gene was polymerase chain reaction (PCR)-amplified using forward primer 5'-CTATGTGCTCCGGATTGGT-3' and reverse primer 5'-AGAGAGGTAGGTGTAGGAGG-3'. PlatinumTaq DNA Polymerase was used for PCR amplification. The following conditions were used: 120 seconds at $95^{\circ} \mathrm{C}$, followed by 30 cycles of 30 seconds at $95^{\circ} \mathrm{C}, 30$ seconds at $60^{\circ} \mathrm{C}$ and 40 seconds at $72^{\circ} \mathrm{C}$ followed by a final 7 minutes at $72^{\circ} \mathrm{C}$. PCR products were purified using QIAquick PCR purification kit. Sequencing was performed using BigDye Terminator v3. ${ }^{1}$ Cycle Sequencing Kit and subsequently purified using BigDye XTerminator purification kit. Capillary electrophoresis was performed on an ABI 3,500 genetic analyser. All kits were used according to manufacturer's instructions.

\section{Results}

The proband, her three children and her sister were heterozygous for a point mutation in the IRE located in the $5^{\prime}$ UTR of the FTL gene on chromosome 19q: G32T (see Figure 1), previously reported as the Paris 2 mutation by Martin et al. ${ }^{11}$ Data on the consanguineous parents of the proband were not available. The two children of the sister were both negative for the point mutation (see Figure 2). 


\section{Discussion}

When facing a high plasma ferritin concentration in an apparently healthy person, it is important - besides excluding $\mathrm{HH}$ in order to prevent organ damage caused by iron overload - to take HHCS into account, despite its rarity, because a mistaken diagnosis of $\mathrm{HH}$ could lead to rapid development of phlebotomy-/iron chelation therapy-induced irondeficient, microcytic anaemia and unnecessary liver biopsies. Thus, the differential diagnosis between HH and HHCS is essential and prevents unnecessary phlebotomy. In this case, plasma biochemical investigation of iron status, family genomic DNA-screening, and an ophthalmological examination are recommended. Craig et al. ${ }^{12}$ even propose cataract morphology to be pathognomonic for HHCS. Furthermore, it is important to consider spontaneous de novo mutations in the FTL gene causing non-hereditary hyperferritinemia cataract syndrome (non-H-HCS), which has been reported by Cao et al. ${ }^{13}$ With this in mind, HHCS should be taken into account even in sporadic cases of early-onset cataract formation.

Patients with HHCS present a versatile phenotype. A clinical variability among subjects sharing the same mutation has been demonstrated, in terms of plasma ferritin levels and time at onset and severity of cataract.9.10,14 Allerson, Cazzola and Rouault found a close correlation between decreases in the IRPS-IREs binding affinity and clinical severity.

\section{Figure 2: Pedigree of the Family with HHCS}

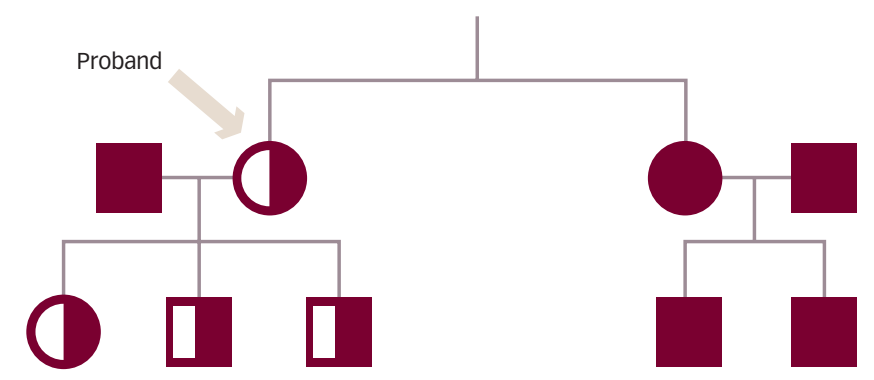

Circles denote female family members; squares denote male family members. White markers indicate affected heterozygous family members. The proband is indicated with a brown arrow. HHCS = hereditary hyperferritinemia-cataract syndrome.

Thus, the severity appears to be determined by the energetics of the binding interaction, and the latter varies among different mutations. ${ }^{15}$

It is likely that naturally occurring polymorphisms within mRNA regulatory proteins contribute to phenotypic diversity, and that other genetic or environmental modifiers play a role in the severity of the disease. Herein, next-generation sequencing studies could be useful in a prospective setting.
1. Bonneau D, Winter-Fuseau I, Loiseau MN, et al., Bilateral cataract and high serum ferritin: a new dominant genetic disorder? I Med Genet, 1995:32:778-9.

2. Girelli D, Olivieri O, De Franceschi L, et al., A linkage between hereditary hyperferritinaemia not related to iron overload and autosomal dominant congenital cataract, Br J Haematol, 1995;90:931-4.

3. Beaumont C, Leneuve P, Devaux I, et al., Mutation in the iron responsive element of the $L$ ferritin mRNA in a family with dominant hyperferritinaemia and cataract, Nat Genet, 1995;11:444-6.

4. Munoz-Munoz J, Cuadrado-Grande N, Moreno-Carralero M et al., Hereditary hyperferritinemia cataract syndrome in four patients with mutations in the IRE of the FTL gene, Clin Genet, 2013:83:491-3.

5. Ferrari F, Foglieni B, Arosio P, et al., Microelectronic DNA chip for hereditary hyperferritinemia cataract syndrome, a mode for large-scale analysis of disorders of iron metabolism, Hum Mutat, 2006;27:201-8.
6. Bertola F Veneri D, Bosio $S$, et al. Hyperferritinaemia without iron overload: pathogenic and therapeutic implications, Curr Drug Targets Immune Endocr Metabo Disord, 2004;:4:93-105.

7. Kroger A, Bachli EB, Mumford A, Gubler C, Hyperferritinemia without iron overload in patients with bilateral cataracts: a case series, J Med Case Rep, 2011;5:471

8. Cazzola M, Bergamaschi G, Tonon L, et al., Hereditary hyperferritinemia-cataract syndrome: relationship between phenotypes and specific mutations in the ironresponsive element of ferritin light-chain mRNA, Blood, 1997;90:814-21.

9. Roetto A, Bosio S, Gramaglia E, et al., Pathogenesis of hyperferritinemia cataract syndrome, Blood Cells Mol Dis, 2002;29:532-5.

10. Cazzola M, Skoda RC, Translational pathophysiology: a novel molecular mechanism of human disease, Blood, 2000;95:3280-8.

11. Martin ME, Fargion S, Brissot $P$, et al., A point mutation in the bulge of the iron-responsive element of the $L$ ferritin gene in two families with the hereditary hyperferritinemia-cataract syndrome, Blood, 1998;91:319-23.

12. Craig JE, Clark JB, MCLeod JL, et al., Hereditary hyperferritinemia-cataract syndrome: prevalence, lens morphology, spectrum of mutations, and clinical presentations, Arch Ophthalmol, 2003;121:1753-61.

13. Cao W, McMahon M, Wang B, et al., A case report of spontaneous mutation $(\mathrm{C} 33>\mathrm{U})$ in the iron-responsive element of L-ferritin causing hyperferritinemia-cataract syndrome. Blood Cells Mol Dis, 2010;44:22-7.

14. Shekunov J, de Groen PC, Lindor NM, et al., Hereditary hyperferritinemia-cataract syndrome in two large multigenerational American families, J AAPOS, 2011:15:356-61.

15. Allerson CR, Cazzola M, Rouault TA, Clinical severity and thermodynamic effects of iron-responsive element mutations in hereditary hyperferritinemia-cataract syndrome, J Biol Chem, 1999;274:26439-47. 